\title{
A new Brazilian species of Loxandrus LeConte, 1852, with description of immatures and notes on natural history (Coleoptera: Carabidae: Loxandrini)
}

\author{
CLEIDE COSTA ${ }^{1,4}$, SERGIO A. VANIN ${ }^{2} \&$ THIAGO R. DE CARVALHO ${ }^{3}$ \\ ${ }^{1}$ Museu de Zoologia, Universidade de São Paulo, Avenida Nazaré, 481, 04263-000 São Paulo, SP, Brazil. E-mail: cleideco@usp.br \\ ${ }^{2}$ Departamento de Zoologia, Instituto de Biociências, Universidade de São Paulo, Rua do Matão, Travessa 14, 101, 05508-900 São \\ Paulo, SP, Brazil. E-mail: savanin@ib.usp.br \\ ${ }^{3}$ Laboratório de Comportamento, Ecologia e Sistemática de Anuros Neotropicais, Universidade Federal de Uberlândia, Av. João \\ Neves de Ávila, 2121, 38400-902 Uberlândia, MG, Brazil.E-mail:Thiago_decarvalho@yahoo.com.br \\ ${ }^{4}$ Corresponding author. E-mail: cleideco@usp.br
}

\begin{abstract}
Loxandrus oophagus sp. nov. is described (type-locality: Uberlândia, State of Minas Gerais, Brazil). Larvae, pupae and adults of the new species of the carabid beetle were collected on foam nests of the anuran Leptodactylus fuscus (Schneider, 1799) in the surroundings of Uberlândia, 18 $55 \mathrm{~S}, 48^{\circ} 17 \mathrm{~W}$ (Brazil, Minas Gerais), at $750 \mathrm{~m}$ altitude. The new species is compared with the similar Loxandrus quinarius Will \& Liebherr, 1997, only known from Santa Cruz, Bolivia, differing by the morphology of tarsomeres. Larvae prey on anuran eggs. Description of the immatures and the natural history of the species are provided. The larva differs from the known larvae of Loxandrus species mainly by being eruciform, glabrous and depigmented, its small head and legs, and the lack of stemmata and urogomphi, representing an unusual last instar type among the Carabidae.
\end{abstract}

Key words: anuran eggs, carabid beetle, egg ectoparasitoidism, Leptodactylus fuscus, nest foam

\section{Introduction}

Larvae, pupae and adults of a carabid beetle collected on different occasions from October 2004 to January 2010, by T. R. de Carvalho, K. G. Facure and A. A. Giaretta in anuran foam nests of Leptodactylus fuscus (Schneider, 1799) were sent to the senior author for identification. Larvae were said to be predators of anuran eggs.

Our studies of the adults' specimens showed that they are consistent with Loxandrus LeConte, 1852 and could be included in the Straneo's seventh group of the genus (1991), which comprises 15 described species. Worldwide Loxandrus includes about 230 recognized species with the majority in South America and others in Central America, North America and Australia (Will, 2008). The systematic position of the genus has been extensively discussed over the last 20 years; the genus was included in the Pterostichinae (as Pterostichini, Reichardt, 1977) but by now some authors place both tribes, Pterostichini and Loxandrini, within a larger concept of Harpalinae (Will et al., 2000; Ober, 2002; Will, 2008).

Loxandrini beetles in the Neotropics are mostly wetland-inhabiting (Will, 2005). The natural history and immature stages of Loxandrus species and related taxa are very poorly known, so far only larvae of two species have been described (Will, 2008). We are describing the larva and the pupa herein since the larvae of the new species are quite different from the known larvae of Loxandrus and of other pterostichines (Bousquet, 1985).

\section{Material and methods}

The biological study of immatures and adults was conducted by T. R. de Carvalho at the "Clube Caça e Pesca Itororó" and on the local road-sides, both being in Uberlândia, State of Minas Gerais, Brazil. The insects were col- 
lected from inside underground nests $(\mathrm{N}>10)$ of terrestrial foam-making frogs Leptodactylus fuscus. Pupae were found excavating the surrounding walls of the underground chambers. The specimens were preserved in ethanol $70 \%$. Some of them were observed in the field, inside the foam nests, while others were collected alive and reared at the Laboratory of Taxonomy, Systematics and Ecology of Neotropical anurans of Uberlândia, Minas Gerais. An entire L. fuscus egg clutch was removed from the nest and transferred to a plastic bowl with flat bottom, kept in laboratory for about twenty days, under environmental conditions of light, humidity and temperature.

The taxonomic study was done at the Laboratory of Coleoptera Systematic, Evolution and Bionomics of the Museu de Zoologia da Universidade de São Paulo by C. Costa and Sergio A. Vanin. Larvae of last instar and adults were dissected in water, under the stereomicroscope. Temporary slides were mounted in Hoyer's medium. Pictures were taken using a Zeiss Microscope Axionskop 2 coupled to a computer and with a SEM Zeiss LEO 440. An adult habitus photo was taken in a Stereomicroscope Leica M205C coupled Magnifier in DV camera Leica DFC 295. Drawings were prepared after photos or made with a camera lucida adapted to a microscope.

\section{Loxandrus oophagus Costa and Vanin, sp nov.}

(Figs 1-48)

Type material. Holotype male: Brazil. Minas Gerais. Uberlândia, 750m altitude, 1855S, 48¹7W, T. R. de Carvalho, K. G. Facure and A. A. Giaretta colls, October 2004 to January 2010. Paratypes (same data as for the holotype): 11 ( 2 dissected, 3 dismembered), 17 ( 02 dissected, 2 dismembered). Other material examined: 108 larvae (5 dissected) and 3 pupae. Holotype, 26 paratypes, 103 larvae and 3 pupae deposited in the Museu de Zoologia, Universidade de São Paulo (MZUSP); 2 paratypes and 5 larvae in the Carnegie Museum of Natural History, Pittsburgh, USA (CMNH).

Description. Length 8.3-9.8 mm. Upper surface black, faintly shiny, not iridescent; antennae, mouthparts, lateral margin of the pronotum and legs paler, rufopiceous to rufotestaceous (Fig. 1).

Head (Figs 2-4). Short, about 0.85 as long as wide; with two supraocular long setae on each side. Eyes strongly protuberant, ocular ratio (width over eyes/width between eyes) 1.6-1.8; frontal sulci (Figs 2,3) well impressed, sharply delimited laterally and posteriorly, forming a lateral, elongate protuberance. Antenna (Fig.4) long extending beyond pronotum base; antennomere 1 with large seta on dorsum, 2 glabrous, 3-11 with an anterior ring of long setae, 4-11 with dense short pubescence, 4 pubescent only in the distal quarter. Front clypeal suture present (Fig. 2). Clypeo-labral suture evident (Fig. 2). Clypeus (Fig. 2) with lateral deep depression, each one with a long stiff seta; lateral margins slightly curved, posterior angles forming a recess to receive frontal protuberance. Labrum (Fig. 2, 6) transverse, 1.75 as wide as long, lateral sides weakly curved, front margin slightly emarginated with three pairs of stiff setae, sizes increasing from middle to lateral sides. Mandibles (Fig. 5) falciform, about twice as long as wide, with small triangular retinaculum near the middle; lateral basal half concave, margin delimited by a longitudinal sinuous carina. Maxilla (Figs 8, 9): basistipes with a long seta near base and palpifer with a very long apical seta; maxillary palpi fusiform (Figs 8,9), palpomere 1 short, 2 longer than 3, curved near base and about 1.5 times as long as 3, 4 slightly longer than 3 and more inflated; palpomeres 1, 2 and 4 asetose, 3 with two distal setae; galea fusiform, asetose but with numeral scattered sensorial pits; lacinia falciform with medial field of spines and setae (Fig. 9). Mentum (Fig. 7) transverse, about three times as wide as long, epilobes rounded distally, about as long as medial area; mentum tooth simple, slightly emarginated and medially impressed at apex, length sub-equal to epilobes; with a pair of long stiff setae at base of mentum tooth; paramedian pits deep. Labial palpi (Fig. 7) fusiform, palpomere 2 slightly longer than 3, with 2 large medial setae and a few distal small setae; palpomere 3 with about 5 scattered small setae and numerous sensorial spots; ligula with glossal sclerite rounded at apex and with 2 large setae; paraglossae long, slender and free.

Thorax. Pronotum transverse, greatest width/length 1.5-1.6, widest near anterior third; disc convex; base bordered at sides (Fig. 4), hind angles not raised; sides sinuate toward at least slightly punctuate base; medial impression and anterior submarginal border entire, not interrupted (Figs 2, 3).

Elytra (Figs 13-15): subparallel, widest at the apical third, 3.6-3.7 times as long as pronotum length, humeral angles moderately prominent, apical sinuation weak but conspicuous; striae complete and strongly punctured throughout most of length, punctures disappearing toward distal quarter; intervals smooth, subconvex; parascutelar stria (Fig. 14) connected to and continuous with stria 1 and elytral basal margin; striae 3-7 not extended to basal 
margin; striae 8 and 9 connected at base and extended to basal margin; basal margin entire; intervals 3, 5 and 7 broader than all others. Metathoracic wings fully developed venation typical for Carabidae (Fig. 22).

Ventral surface with pentagonal and hexagonal microreticulate surface throughout. Metanepisternum (Figs 1012) elongate, about 3 times as long as wide, strongly narrowed posteriorly, lateral margin longer than medial margin. Mesepimeron and metanepisternum coarsely punctuate. Discrimen (Fig. 11) and transverse suture present.

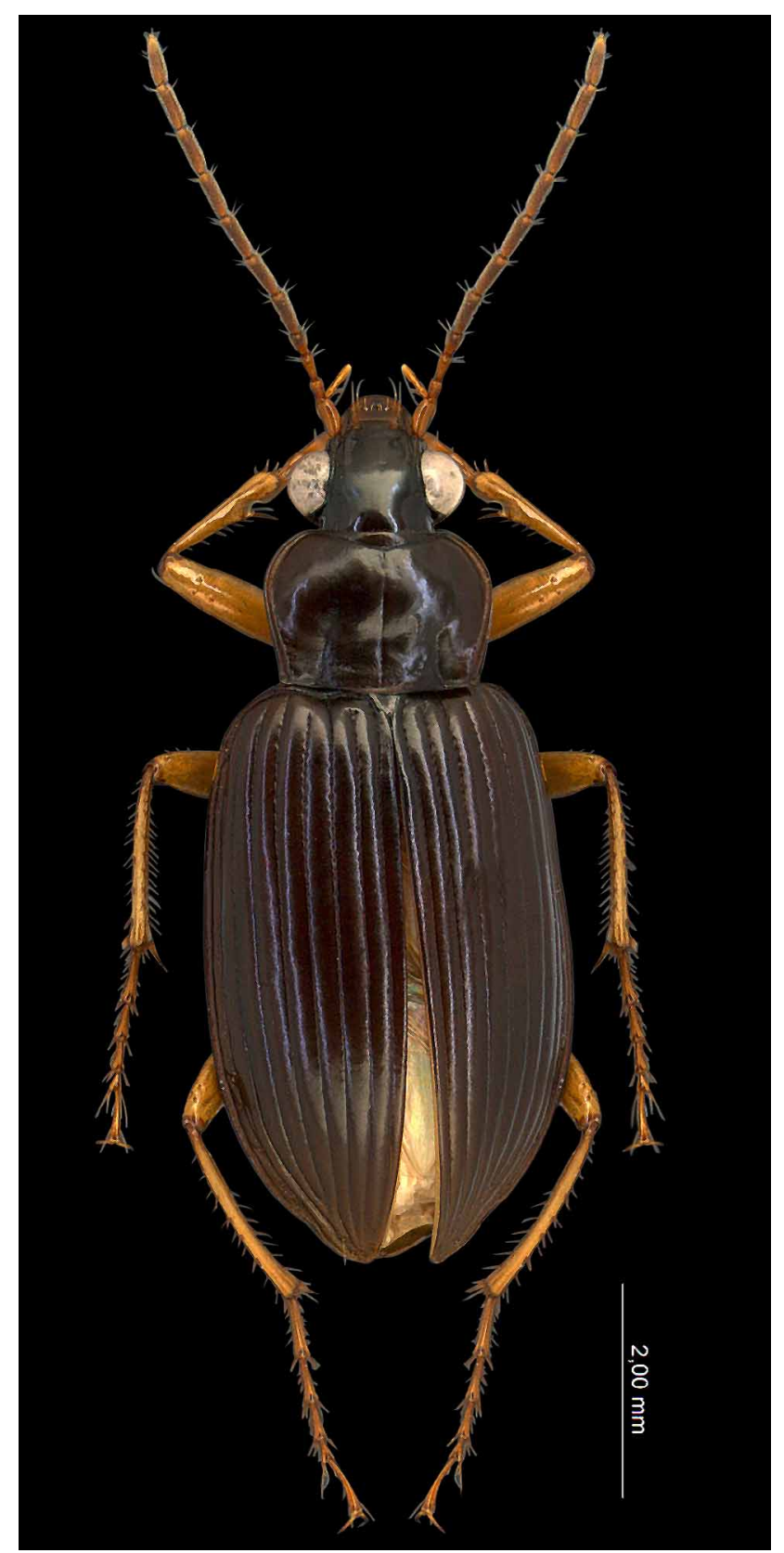

FIGURE 1. Loxandrus oophagus Costa and Vanin, adult habitus (photo, R. Kawada).

Legs (Figs 16-18) slender; pro- and metatibiae with internal and external carina, mesotibiae simple; protarsomere 1 in male with dorsal and internal sulci, although not conspicuous in all specimens; female only with internal sulci; meso- and metatarsomeres 1-4 in male, and 1-3 in female, with internal and external sulci distinct (50X), in female, meso- and metatarsomeres with only shallow internal sulcus; tarsomeres 1 longer than tarsomere 5, tarsomere 5 ventrally setose.

Abdomen (Fig. 10). Ventrites 1 and 2 laterally rugose to punctate; 5-6 with a medial pair of stiff setae.

Female genitalia (Figs 19-21). Gonocoxite 1 glabrous; gonocoxite 2 conical, sides feebly curved and tapering toward apex, 2-2.3 times as long as wide, with sensorial punctures on anterior third and few short and stiff setae at apex. 
Male genitalia (Figs 23-29). Penis asymmetrical, strongly curved with dorsal ostium; endophallus uniformly covered with microtrichiae and with five elongate oval spiny sclerites. Left paramere broader and less sclerotised than right paramere.
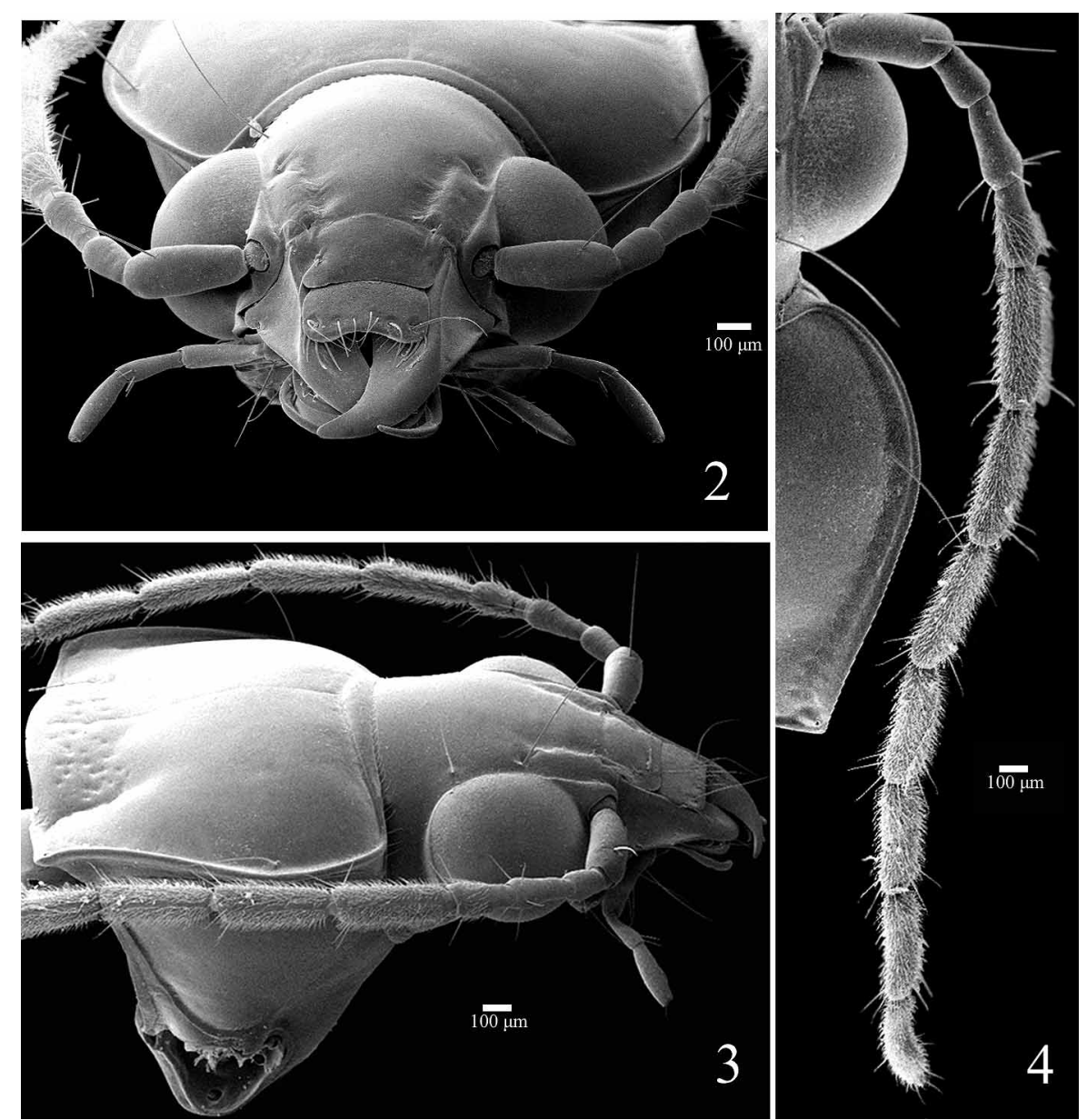

FIGURES 2-4. Loxandrus oophagus Costa and Vanin, adult male: fig.2: head and prothorax (frontal view); fig. 3. head and prothorax (lateral view); fig. 4. head and prothorax (dorsal view).

Etymology. oophagus, from the Greek, oön = egg and phagos = phagein = to eat; in reference to the feeding habit of the species.

Remarks. Loxandrus oophagus is very similar to Loxandrus quinarius Will \& Liebherr, 1997, which is only known from the female holotype from Santa Cruz, Bolivia. These species can be distinguished by the structure of their tarsomeres. In L. oophagus the meso- and metatarsomeres 1-4 of males have the internal and external sulci distinctly visible (50X), while in the females the internal and lateral sulci are found only on the meso-and metatarsomeres $1-3$, and on the fourth represented by a shallow internal sulcus. In L. quinarius (female holotype), the internal and external sulci are present in meso- and metatarsomeres 1-4. Another possible difference is the form of the frontal sulci, convergent to the base in L. quinarius and divergent in L. oophagus. However this character varies among individuals in the series of $L$. oophagus studied.

Loxandrus quinarius was compared to L. strigomeroides Straneo, 1991 by Will and Liebherr (1997). The two species are very similar and share the very large and prominent eyes; a condition considered by Straneo (1991) as being very unusual among Loxandrus species, that is also shared by L. oophagus.

Loxandrus oophagus can be included with the 15 other species of Straneo's (1991) seventh group, that all share the following characteristics: elytra black or brown, without red spots or patterns, not iridescent; pronotum with base bordered at sides, hind angles not raised; sides sinuate or subsinuate toward at least slightly punctuate base, anterior submarginal border entire. Like Straneo's (1991) "Section A", L. oophagus has ventral setae on fifty tarsomeres. However, Straneo's groups of species were constructed using only a few characteristics that have not been subjected to phylogenetic analysis. Therefore the placement should be considered as provisional, until a cladistics analysis of Loxandrus is performed (Will and Liebherr 1997, Will, 2008) to test the monophyly of the genus. 


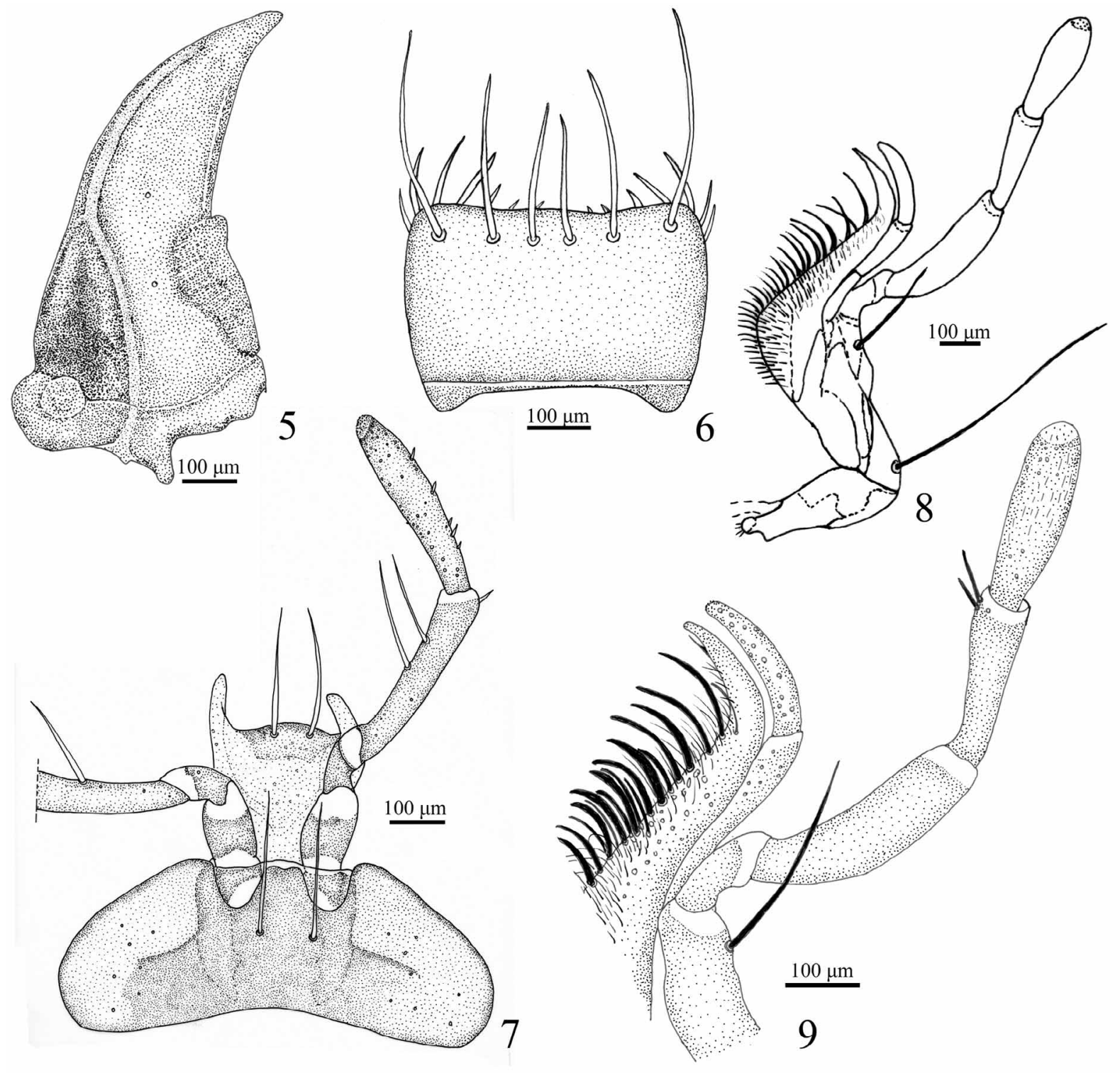

FIGURES 5-9. Loxandrus oophagus Costa and Vanin, adult female: fig. 5 mandible; fig.6 labrum; fig. 7 labium; fig. 8 maxilla; fig. 9 maxillary palp and apices of galea and lacinia.

Two species actually assigned to Adrimus Bates, A. claripes and A. latibasis, both described by Straneo (1993), are also very similar to L. oophagus. The three species share the very large and convex eyes, the pronotum with deep median impressed line, and the space between the pronotal basal impressions depressed and coarsely punctuate. Adrimus claripes is known from the State of Alagoas in Northeastern Brazil. It is distinguished by the underside impunctate, except the metanepisterna, which are strongly punctuate, while in L. oophagus the metanepisterna, the mesenepisterna and the laterobasal sides of ventrite are strongly punctuate. Adrimus latibasalis is known from Salta Orán, Argentina. It differs chiefly by the pronotum shape, with sides not sinuate before the basal angle, while in L. oophagus the lateral margins of the pronotum are conspicuously sinuate.

Mature larva description (Figs. 30-35, 37-47). Length: 12.7 - $14.5 \mathrm{~mm}$. Body elongate, eruciform, slightly flattened, with micro setaceous projections on thoracic segments II-III and abdominal segments I-IX (Figs 39 and 42); body unevenly pigmented, varying from white to yellowish, pronotum with two darker small flattened anteromedian patches; glabrous at low magnification (40X).

Head (Figs 31, 37-38) small, prognathous and slightly protracted, quadrangular and slightly round-sided, much narrower than prothorax. Posterior edge as seen from above broadly emarginated. Epicranial stem absent; frontal arms slightly lyriform, vaguely indicated posteriorly. Endocarinae absent. Parietale without stemmata. Cervical groove absent. Antennae (Fig. 34) small, 4-segmented; antennomere 1 and 3 about as long as wide, 2 transverse 
half length of antennomeres 1 or 3; discoidal sensorium lying at outer corner of antennomere 3. Frontoclypeal suture absent. Nasal transverse, rounded, with a few sensorial punctures; irregularly microserrate (Figs. 31, 33). Adnasal absent. Mandibles (Fig. 32) symmetrical, falcate and slender, with a sharp retinaculum placed medially in strongly curved mesal margin. Maxillae with cardines small and transverse; stipes broadly elongate; galea bi-articulated, basal article large and conical, distal article small and spiniform (Figs. 35, 37); palp 3-segmented, palpifer transverse, palpomeres 1-3 about of same length, decreasing in width. Labium (Figs 35, 37) with mentum sclerotised, submentum small, transverse, membranous and fused to elongate submentum; mentum quadrangular, lateral margins curved, labial palp 2-segmented, basal segment broader; hypopharynx with microtrichiae. Posterior tentorial pits conspicuous.

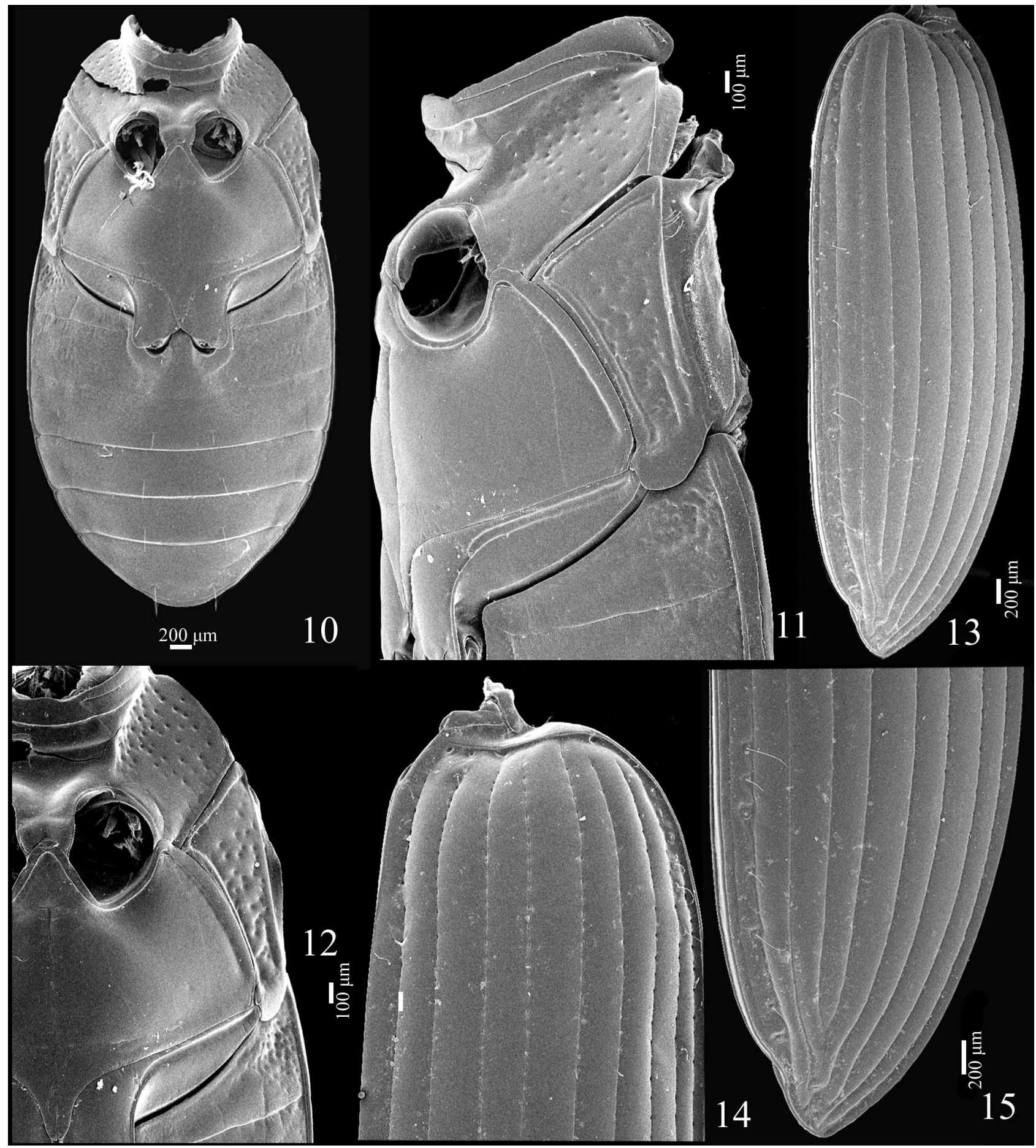

FIGURES 10-15. Loxandrus oophagus Costa and Vanin, adult male electron microscopy photos: fig. 10 meso - metathorax and abdomen (dorsal view); fig. 11 meso - metathorax,(lateral view, note discrimen); fig. 12 meso - metathorax (dorsal view, note punctures); figs 13-15 elytron. 

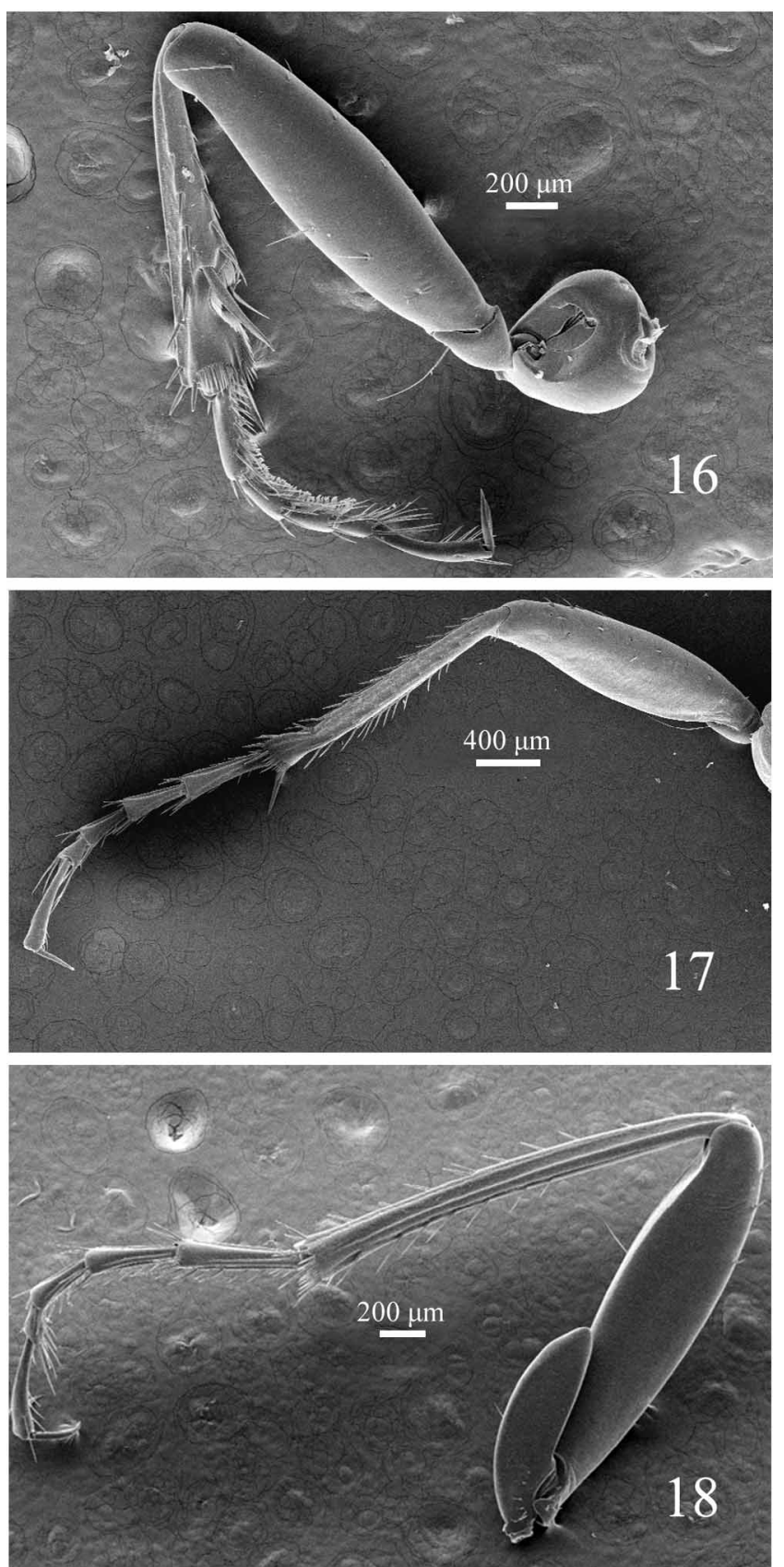

FIGURES 16-18. Loxandrus oophagus Costa and Vanin, adult male electron microscopy photos: figs 16-18, pro - meso and metalegs.

Thoracic and abdominal segments I-VIII moderately to strongly transverse, IX conical elongate, $\mathrm{X}$ ventral, small, tubular, forming two prolegs bearing coarse pointed microsculptures (Figs 30, 46-47); thoracic terga II-III and abdominal terga I-IX with very small setiferous projections (Figs 39 and 42); thoracic terga increasing in length and width from I to III. Protergum with two small flattened pigmented anteromedian patches (Fig. 30). Thorax spiracles between pro- and mesothorax (Figs. 30, 40). Abdominal spiracles annular located dorsally on lateral portion of tergites I-VIII (Figs 30, 41). Legs (Figs 43-45) of similar size, with two unequal claws.

Remarks. Some features of the last instar larva of the new species are unusual among carabids, and seem to be adaptations to the peculiar life history of the species. The body is eruciform, with reduced head and legs (Fig. 30). The integument is weakly sclerotized, glabrous, with a few micro setae restricted to head appendages (Figs. 34, 35), body tubercles (Figs. 39, 42) and legs (Figs. 43-45). The larva is completely blind and the parietale area has no trace of stemmata (Figs. 37, 38). Abdominal segment $9^{\text {th }}$ is without urogomphi. The abdominal segment $10^{\text {th }}$ is very small, tubular and ventral, forming two projections bearing coarse pointed microsculptures, which function as crochets of pro-legs (Figs. 46, 47). 
Larvae morphology of two species of Loxandrus was previously studied by Bousquet (1985) - L. velocipes Casey, 1918 - and by Will (2008) - L. semperfidelis Will, 2008. The three instars of the former species were described, but only the first instar of the latter is known. The first instar larvae of the two Loxandrus species are very similar. The third instar larva of $L$. velocipes differs from the last instar of $L$. oophagus in all the features mentioned above, plus the presence of a cervical groove, absent in L. oophagus. Further, the shape of antennal sensorium is discoidal in L. oophagus and papiliform in L. semperfidelis.

The urogomphi may be absent mainly in the first instar of some other carabid species, e.g.: some species of Pseudomorphinae (Erwin, 1981), Adelotopus dytiscoides Newman, 1840 - Pseudomorphinae - living under bark (Arndt et al. 2005) and Pheropsophus hispanicus Dejean \& Latreille, 1823 - Brachininae - ectoparasitic on pupae of Dineutes assimilis Kirby, 1837 - Gyrinidae - (Jeannel, 1970). In some carabids, mainly ectoparasitoids species, the urogomphi are present and well developed in the first triunguliniform instar, but can be reduced or even absent in the older instars (Zetto Brandmayr et al., 1998).
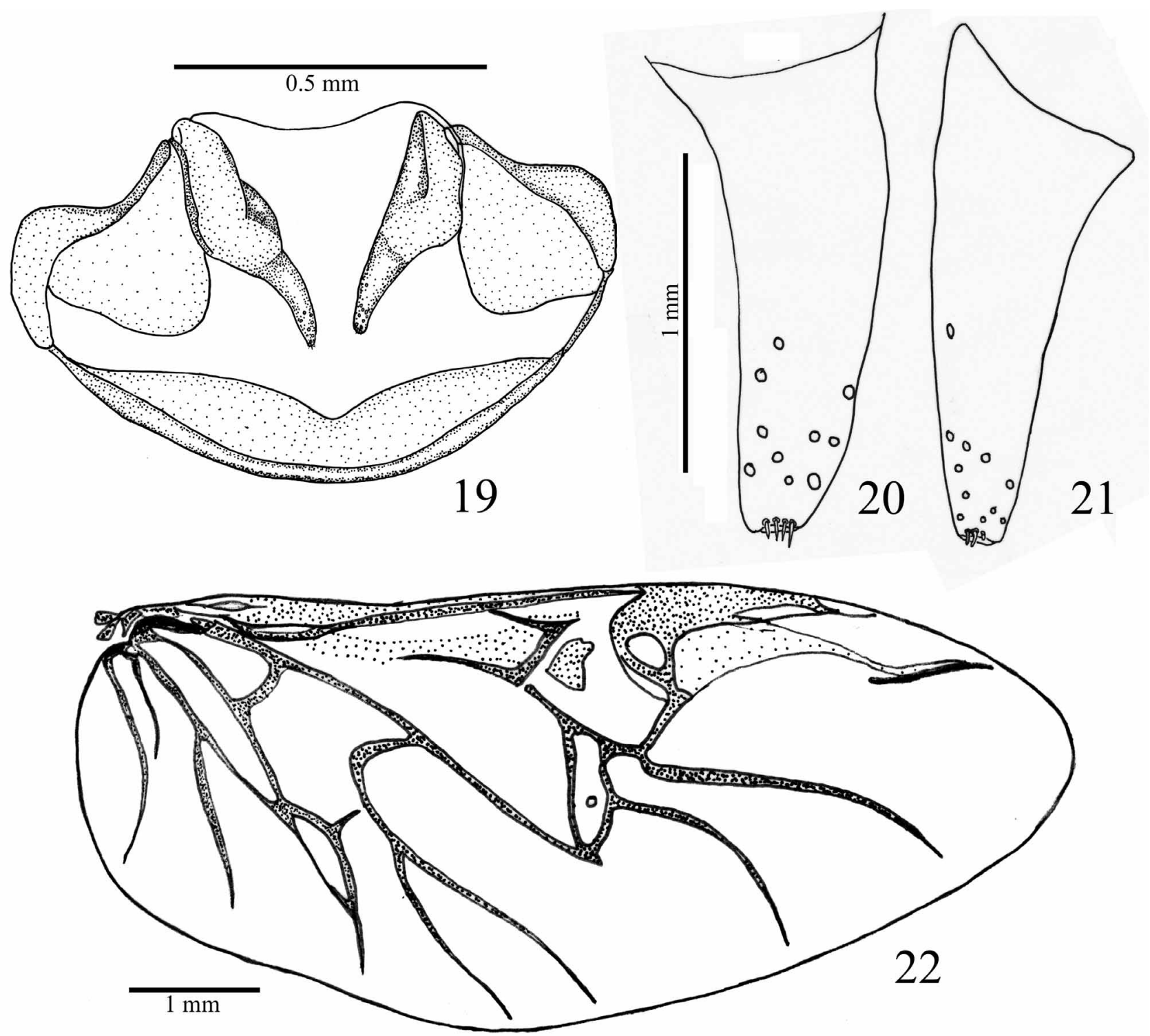

FIGURES 19-22. Loxandrus oophagus Costa and Vanin, fig. 19 adult female genitalia; figs 20-21 gonocoxites; fig.22 male metathoracic wings.

Pupa description (Fig. 36). Length 7.8-8.3 mm. Adecticous and exarate. Body convex, cream to yelowishwhite, with patches of short hairs. Head completely covered with pronotum in dorsal view. Eyes very large, convex and prominent. Mouthparts visible in ventral view. Antennae lying parallel to ventral sides of prothorax. Pronotum small, tranverse with small setae at the anterior margin and near the posterior third. Pterothecae extending up to 
fourth ventrite. Legs free, visible in ventral view. Abdomen with nine visible tergites (one of them only visible apico-laterally) and seven visible sternites. Tergite IX rounded. Lateral tubercles on abdominal segments II-VI with two very short setae. Spiracles I-VI in the pleural membrane, visible from dorsal view.

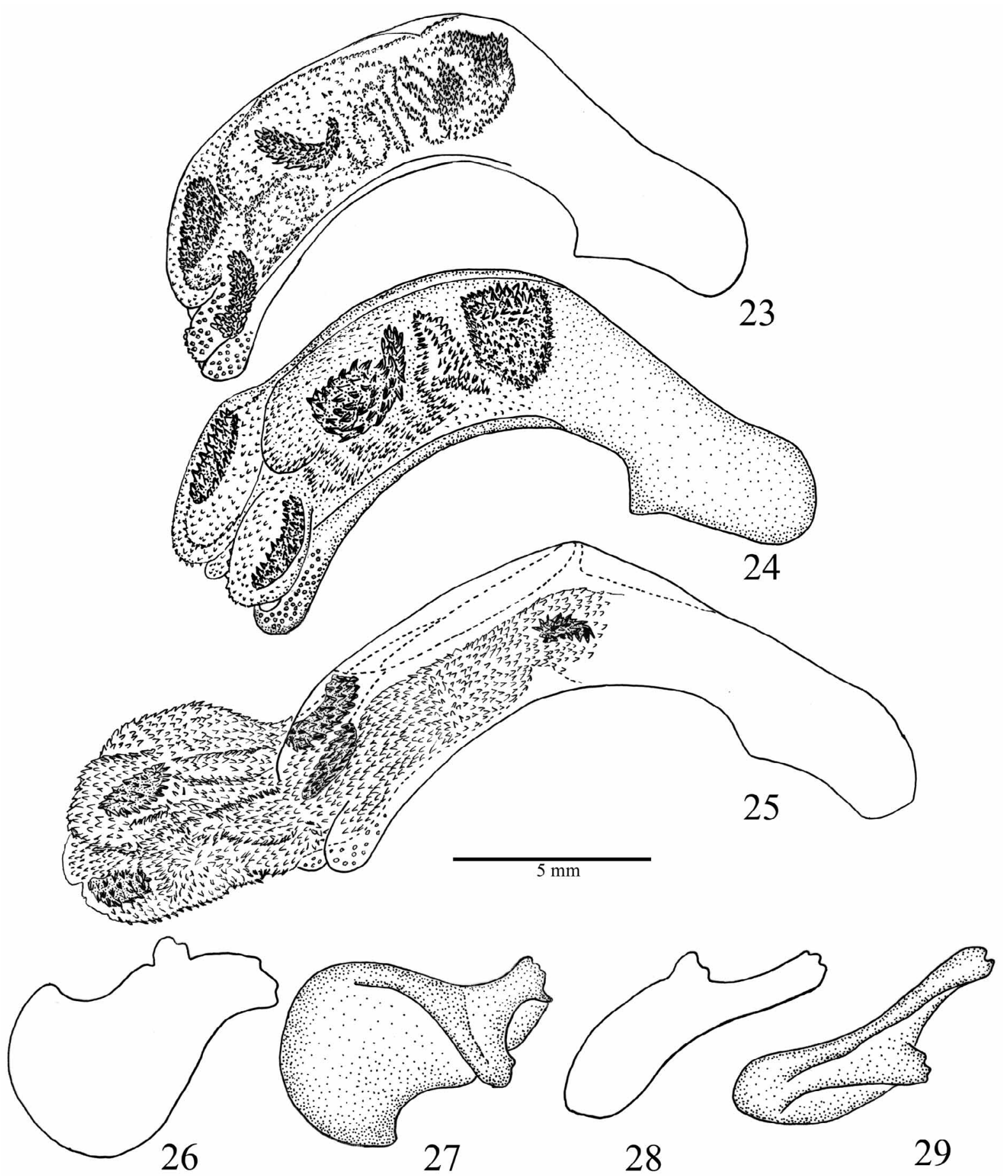

FIGURES 23-29. Loxandrus oophagus Costa and Vanin, figs 23-29 adult male genitalia.

Natural history. Adults of Loxandrus oophagus were found (1 individual, N=10; 2 individuals, $\mathrm{N}=5$ ) at the bottom of foam nests of the frog Leptodactylus fuscus (Figs 48-49). The frog nests are underground chambers constructed at the bottom of gullies or at the border of temporary pools. Mating and oviposition site were not observed, as well as larvae of first and intermediate instars. Adults were observed walking on the surface of the foam nest and also crossing through the foam to reach the bottom of the chamber. Adults were never observed feeding inside or outside the nest. The larva completes its life cycle inside the nest and feeds only on the frog's eggs. Larvae eat eggs but they have never been seen feeding on embryos, hatchlings or tadpoles. The number of larvae observed inside 
foam nests varied from 7 to $23(\mathrm{~N}=20)$. After larval development is accomplished the larvae stop feeding. Ten infested foam nests have been observed. The larvae require 3-5 days to consume the entire egg clutch. Afterwards they start moving to the surrounding walls of the nest to pupate in the ground. Pupation phase lasts about 5 days $(\mathrm{N}=5)$ after which teneral adults were found. These data suggest that the relationship between the carabid beetle and the foam nest is obligatory.
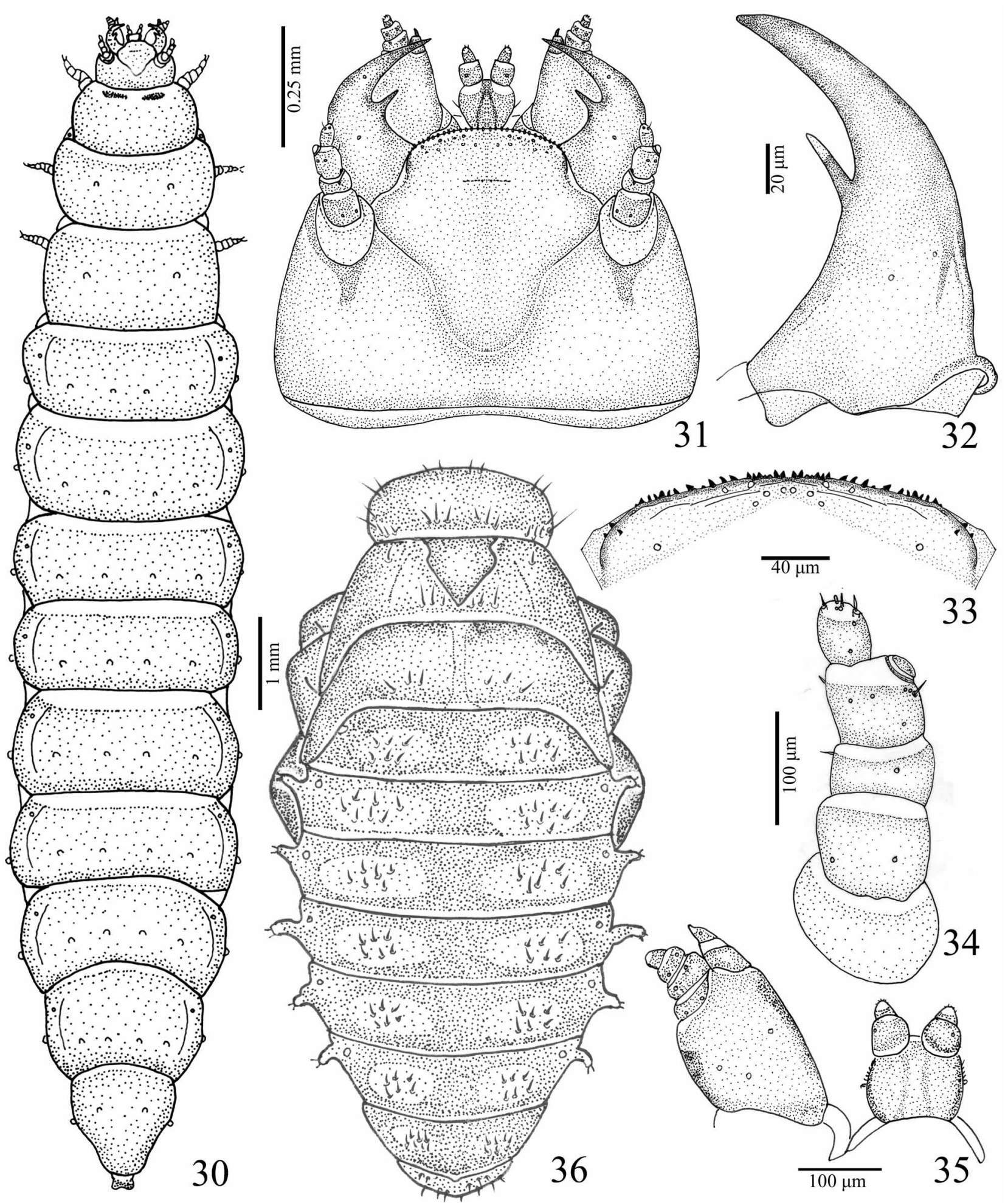

FIGURES 30-36. Loxandrus oophagus Costa and Vanin, last instar larva: fig. 30 habitus; fig. 31 larval head (dorsal); fig. 32 larval mandible; fig. 33 detail of the nasal anterior margin (dorsal); fig. 34 antenna; fig. 35 larval maxilla and labium; fig. 36 pupa (dorsal view). 


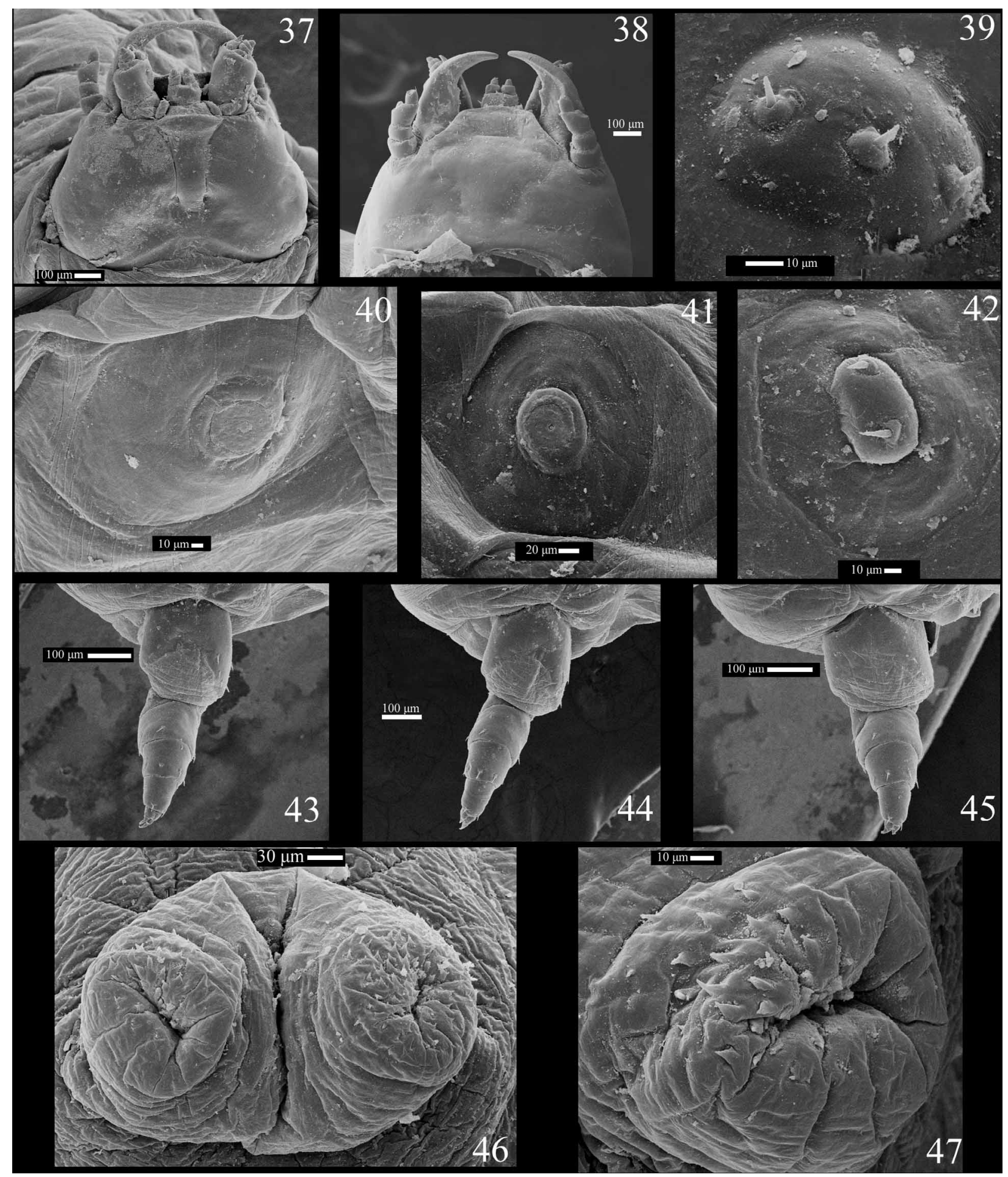

FIGURES 37-47. Loxandrus oophagus Costa and Vanin, last instar larva, electron microscopy photos: fig. 37 head (ventral view); fig. 38 head (dorsal view); fig. 39 body micro setiferous projections; fig 40 thoracic spiracle; fig. 41 abdominal spiracle; fig 42 body micro setiferous projections; figs 43-45 pro - meso - and metalegs; figs 46-47 prolegs of the IX abdominal segment.

Discussion and conclusions. Very little is known about the natural history of Loxandrini. Most larvae of carabid beetles are predators and search for food actively. Their bodies are usually campodeiform, well sclerotised and pigmented, have proportionally large head with stemmata, long or stout cursorial legs, and bear fixed urogomphi (Crowson, 1981; Lövei \& Sunderland, 1996).

The external larval features that distinguish the mature larva of Loxandrus oophagus from the larvae of most other predaceous carabids are likely specializations related to their cryptic life history in anuran foam nests. The 
most notable differences from a typical carabid larva are the eruciform body, that is glabrous and depigmented, head and legs that are small, and the absence of both stemmata and urogomphi. The foam nest provides shelter, a suitable humid environment and an abundant food source represented in the nutritive anuran eggs. The larva has limited mobility and is restricted to the foam nest, but has no need to search for food.

Some specialist feeder carabid beetles develop in nests of different ant or termite species, feeding on the hosts or their broods. Larvae or adults of myrmecophile carabids usually invade the nests through their entrances (Dinter et al., 2002). Larvae of some of these myrmecophile or termitophile carabid species also have some of the adaptive features present in L. oophagous, developed by convergent evolution to nest environments (Erwin, 1979; Erwin, 1981).

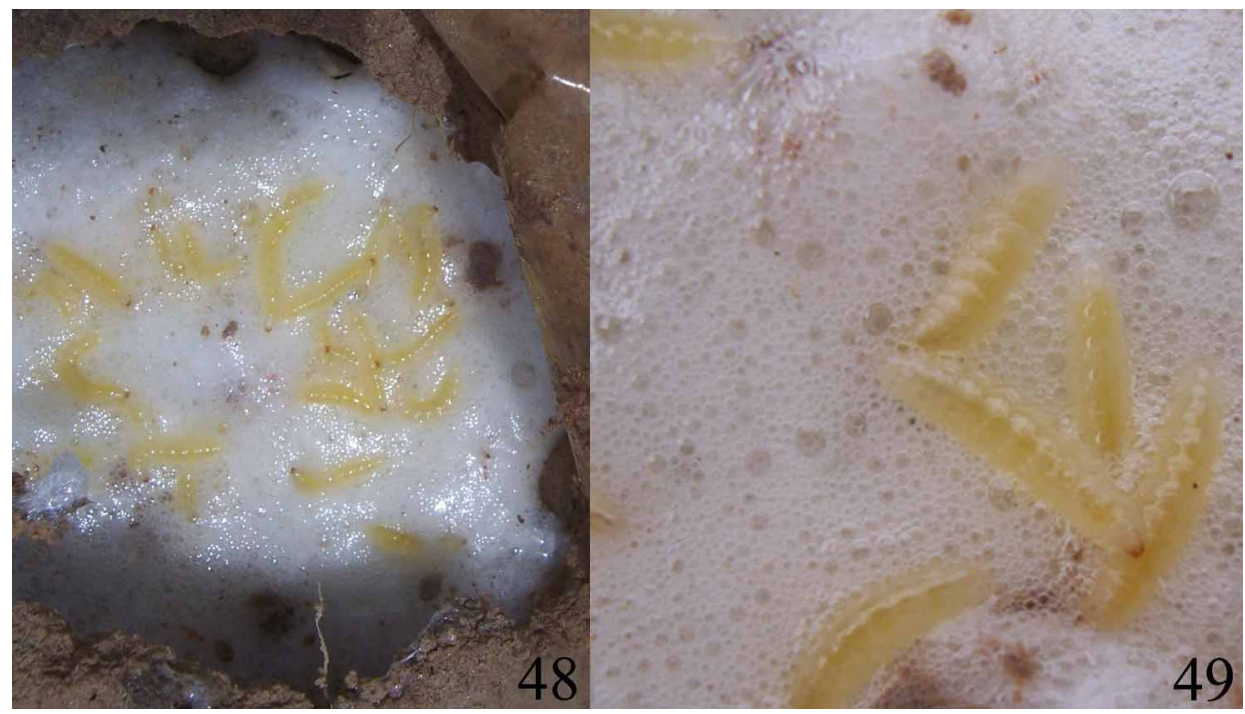

FIGURES 48-49. Loxandrus oophagus Costa and Vanin, figs 48-49 last instar larvae infesting foam nest of Leptodactylus fuscus (general aspect and detail). (Photos T. R. de Carvalho)

The adults of L. oophagus do not have any conspicuous features adaptive to this particular habitat, the foam nest. The only notable characteristic is their very large eyes, a feature shared with L. quinarius and L. strigomeroides and considered very unusual in Loxandrus (Straneo, 1991, Will \& Liebherr, 1997).

According to the known natural history of Loxandrus species, two natural traits can be distinguished, considering larval morphology and behavior. One has adaptations to a solitary and predator way of life, as presented by the Northern American L. velocipes, while the other is adapted to consume eggs inside a cryptic environment, as reported herein to the South American L. oophagus.

Carnivorous carabid beetles commonly attack other arthropods, more rarely other small invertebrates, such as Gastropoda and Oligochaeta, and occasionally they prey on small amphibians or fishes (Crowson, 1981; Toledo, 2005). According to Jäch (1998) several species of Carabidae may be found foraging under water: adults and larvae of Carabus clathratus L. 1758, C. variolosus F. 1787, C. menetriesi Hummel, 1827 (Carabinae) are reported to hunt for snails, crustaceans, insect larvae, tadpoles, and small fishes under water. Adults are said to store air under their elytra. According to Elron et al. (2007) there are three reported cases of carabid beetles preying on amphibians, all belonging to the Chlaeniini (= Callistini). In all cases, these carabid larvae attack anuran juveniles on the ground, near their breeding sites in the spring. According to Duellman \& Trueb (1986), terrestrial eggs of various groups of anurans are eaten by a variety of insects, especially carabids and tenebrionids. Larvae of Beckeriella niger (Williston, 1897) (Ephydridae, Diptera) were reported consuming eggs, embryos and tadpoles in foam nests of the leiuperid Physalaemus cuvieri Fitzinger, 1826 in Brazil (Bockermann, 1957; Menin \& Giaretta, 2003). Consequently, this is the first report of predation on anuran eggs by a carabid larva.

\section{Acknowledgments}

To Robert Davidson (Carnegie Museum of Natural History) who kindly sent us photos and useful information about the holotype of Loxandrus quinarius. To Simone P. Rosa (Museu de Zoologia, São Paulo) for help in the 
electronic treatment of the figures and review of the MS. To Lara Maria Guimarães (Museu de Zoologia, USP) for the electronic microscopy photos. To Ricardo Kawada (Faculdade de Filosofia Ciências e Letras de Ribeirão Preto, USP and Museu de Zoologia, USP), for the adult stereomicroscope photo. Thanks are also given to Kátia G. Facure who firstly discovered the carabid larvae in the nest foam and to Ariovaldo A. Giaretta for help during the field work (Universidade Federal de Uberlândia, Minas Gerais). A special thank to two anonymous referees for important comments and suggestions that greatly improved the paper. To Conselho Nacional de Desenvolvimento Científico e Tecnológico (CNPq) for the Research Grant 302721/2007 - 0 to C. Costa. To Ricardo Pires Vanin for the electronic treatment of the figures $1-4$.

\section{References}

Arndt, E., Beutel, R.G. \& Will, K. (2005) 7.8. Carabidae Latreille, 1802 p. 119-146. In: Coleoptera, beetles Volume 1: Morphology and Systematics (Archostemata, Adephaga, Myxophaga, Polyphaga partim). In: N. P. Kristensen \& Beutel, R. G. (eds). Handbuch der Zoologie/Handbook of Zoology, Band/Volume IV: Arthropoda: Insecta.1 ed. Berlin: Walter de Gruyter GmbH \& Co.KG, p. 1-567.

Bockermann, W.C.A. (1957) Frog eggs parasitized by dipterous larvae. Herpetologica, 13, 231-232.

Bousquet, Y. (1985) Morphologie comparée des larves de Pterostichini (Coleoptera: Carabidae): descriptions et tables de détermination des espèces du nord-est de l'Amerique du nord. Le Naturaliste Canadien, 112, 191-251.

Crowson, R.A. (1981) The Biology of Coleoptera. Academic Press, London, xii +802 p.

Duellman, W.E. \& Trueb, L. (1986) Biology of Amphibians. Macgraw-Hill, New York, xx + 670 p.

Dinter, K., Paarmann, W., Peschke, K. \& Arndt, E. (2001) Ecological, behavioural and chemical adaptations to ant predation in species of Thermitophilum and Graphipterus (Coleoptera: Carabidae) in Sahara Desert. Journal of Arid Environment, 50 (2), 267-287.

Elron, E., Shlagman, A. \& Gasith, A. (2007) First detailed report of predation on Anuran metamorphs by terrestrial beetle larvae. Herpetological Review, 38(1), 30-33.

Erwin, T.L. (1979) A review of the natural history and evolution of ectoparasitoid relationships, pp. 479-484. In Erwin, T.L., Ball G.E., \& Withehead, D. R. (Eds). Carabid beetles: their evolution, natural history and classification. Proceedings of the First International Symposium of Carabidology, Washington, D.C., 1976, W. Junk, Boston, MA.

Erwin, T.L. (1981) A synopsis of the immature stages of Pseudomorphini (Coleoptera: Carabidae) with notes on tribal affinities and behavior in relation to life with ants. The Coleopterists Bulletin, 35(1), 53-68.

Erwin, T.L. \& Sims, L.L. (1984) Carabid Beetles of the West Indies (Insects: Coleoptera): A Synopsis of the Genera and Checklists of the Tribes of Caraboidea, and of the West Indian Species. Quaestiones Entomologicae, 20, 351-466.

Jäch, M.A. (1998) Annotated check list of aquatic and riparian/littoral beetle families of the world (Coleoptera). In M.A. Jäch \& Ji. L. (eds.): Water Beetles of China, Vol. II, 25-42.

Jeannel, R. (1970) Coléopteres, Carabiques deuxième partie. Faune de la France. T. 40. Kraus Reprint, Nendeln, Liechtenstein, $1173 \mathrm{p}$.

Lövei, G.L. \& Sunderland, K.D. (1996) Ecology and behavior of ground beetles (Coleoptera: Carabidae). Annual Review of Entomology, 41, 231-256.

Menin, M. \& Giaretta, A.A. (2003) Predation on foam nests of leptodactyline frogs (Anura: Leptodactylidae) by larvae of Beckeriella niger (Diptera: Ephydridae). Journal of Zoology, London, 261, 239-243.

Ober, K.A. (2002) Phylogenetic relationships of the carabid subfamily Harpalinae (Coleoptera) based on molecular sequence data. Molecular Phylogenetics and Evolution, 24, 228-248.

Reichardt, H. (1977) A synopsis of the genera of Neotropical Carabidae (Insecta, Coleoptera). Quaestiones Entomologicae, 13, 346-493.

Straneo, S.L. (1991) South American species of Loxandrus LeConte, 1852 (Coleoptera: Carabidae: Pterostichini). Annals of Carnegie Museum, 60 (1), 1-62.

Toledo, L.F. (2005) Predation of juvenile and adult anurans by invertebrates: current knowledge and perspectives, Herpetological Review, 36(4), 395-400.

Will, K.W. (2005) The Neotropical genera Oxycrepis Reiche and StolonisMotschulsky: a taxonomic review, key to the described species and description of new Stolonis species from Ecuador (Coleoptera: Carabidae: Loxandrini). Zootaxa, $1049,1-17$.

Will, K.W. (2008) A new species of Loxandrus Leconte (Coleoptera:Carabidae: Loxandrini) from South America. Annals of Carnegie Museum, 77 (1), 205-210.

Will, K.W. \& Liebherr, J.K. (1997) New and little known species of Loxandrus LeConte 1852 (Coleoptera:Carabidae). Studies in Neotropical Fauna and Environment, 32, 230-238.

Will, K.W., Attagalle, A.B. \& Herath, K. (2000) New defensive chemical data for Ground Beetles (Coleoptera: Carabidae): interpretations in a phylogenetic framework. Biological Journal of the Linnean Society, 71, 459-481.

Zetto Brandmayr, T., Giglio, A., Marano, I. \& Brandmayr, P. (1998) Morphofunctional and ecological features in carabid larvae: a contribution to distinguish between affinity and convergence, pp. 449-490. Atti del convegno XX International Congress of Entomology, Firenze 28-31 agosto 1996. Torino: Museo Regionale di Scienze Naturali di Torino. 